\title{
Prediction of Elastic Modulus and Mid-span Deflection of Bamboo-wood Composite Laminates
}

\author{
Aonan Chen, ${ }^{\mathrm{a}}$ Yi Liang, ${ }^{\mathrm{a}}$ Zhilin Jiang, ${ }^{\mathrm{a}}$ and Jianping Sun ${ }^{\mathrm{a}, \mathrm{b}, *}$ \\ To better guide the manufacturing of bamboo-wood composite laminates, \\ classical theory, first-order shear theory, and finite element method were \\ used to predict the elastic modulus and deflection of bamboo-wood \\ composite laminates. The influence of the adhesive layer on the elastic \\ modulus and deflection of composite materials was considered. The effect \\ of transverse shear on the mechanical properties of materials became \\ smaller and smaller with an increasing span-to-height ratio. The effects of \\ the adhesive layer on the elastic modulus and deflection were $\pm 0.5 \%$ and \\ $-0.1 \%$ to $0.3 \%$, respectively. The transverse elastic modulus and mid-span \\ deflection predicted by the three methods were quite different from the \\ experimental results. When the span-to-height ratio was equal to 20 , the \\ prediction error of longitudinal elastic modulus by the three methods was \\ less than $6 \%$, which can be used to predict the elastic modulus of \\ composite materials. The results provide a novel method to predict the \\ properties of bamboo-wood composite laminates.
}

Keywords: Bamboo-wood composite laminates; Classical theory; First-order shear theory; Finite element

Contact information: a: Materials, School of Resources, Environment and Materials, Guangxi University, Nanning 530004, China; b: State Key Laboratory of Featured Metal Resources and Advanced Materials, Guangxi University, Nanning 530004, China; *Corresponding author: jpsun@gxu.edu.cn

\section{INTRODUCTION}

A bamboo-wood composite laminates is a compound panel comprising glued bamboo and wood together in the same or different structural units (Guo et al. 2016). It combines the excellent properties of bamboo and wood, which make it widely used as structural materials in the field of engineering structures, such as container floors, car floors, and building templates. In addition, modified bamboo-wood composites serve as functional materials for electric heating and corrosion protection.

Due to the decrease in forest resources, the contradiction between the supply and demand of wood is increasingly prominent (Ettelaei et al. 2019). In addition, timber prices have fluctuated frequently and have maintained an upward trend in recent years. According to data from Random Lengths, a timber industry research organization, the price of timber in the United States reached \$1,495 per thousand board feet in May 2021, a 318\% increase compared to April 2020. Therefore, it is necessary to find a material that can replace wood to alleviate the problem. Bamboo, like wood, is a natural polymer similar to those of hardwood (Rao et al. 2018; Banik 2020). Moreover, bamboo is the fastest-growing and highest-yielding renewable natural material available to humans (Guo et al. 2016). Bamboo culms can be cut and used after three to five years, depending on the species (Lee et al. 2012; Liliefna et al. 2020). These make it a great potential alternative to wood (Verma et al. 2014; Banik 2018). By gluing wood and bamboo together to composite materials, the excellent characteristics of bamboo and wood were combined to obtain the double benefit of ensuring the quality of the products and reducing the production cost. 


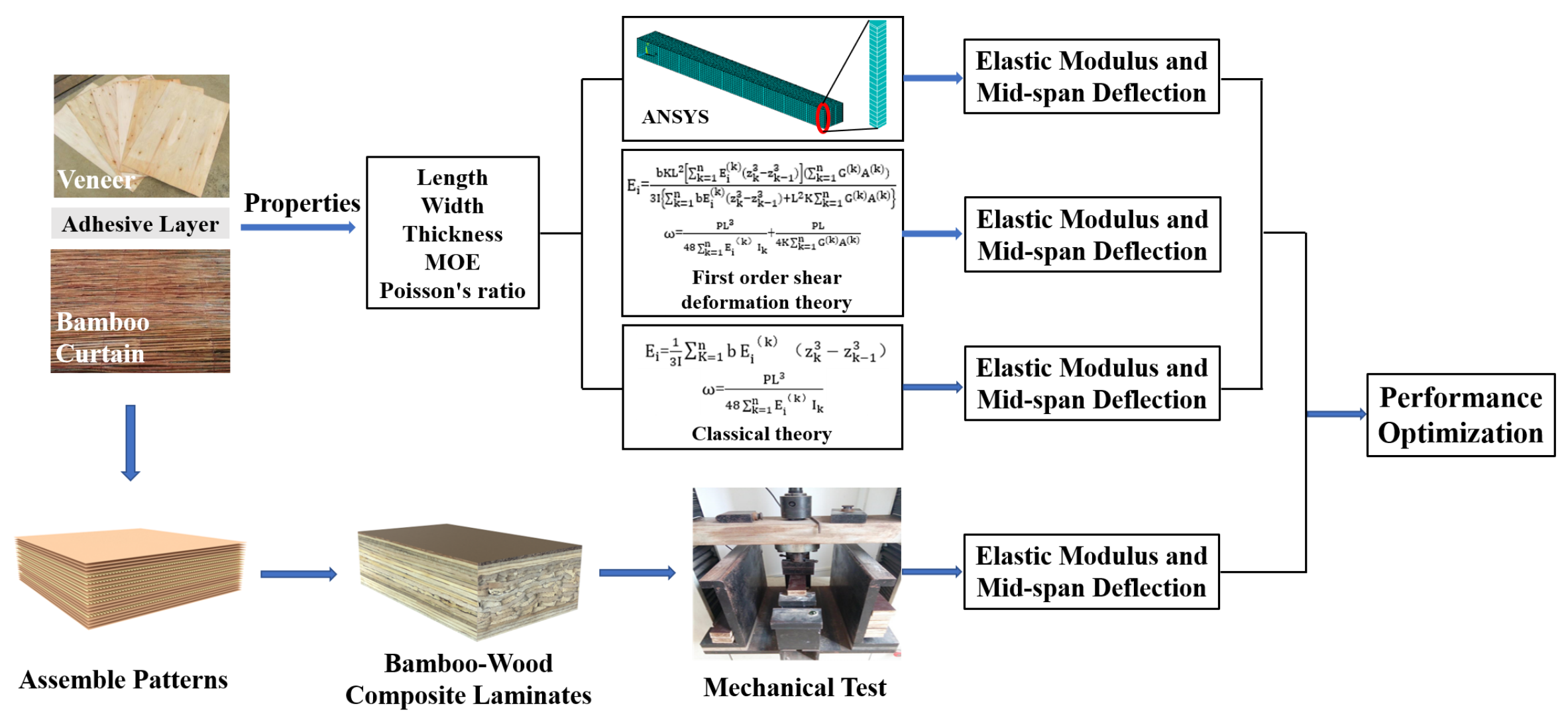

Fig. 1. Schematic chart of experiments 
As an engineering material, the mechanical properties of bamboo-wood composite laminates are one of the important indexes for industrial requirements. The elastic modulus, which is an essential parameter of the macroscopic mechanical properties and reflects materials' ability to resist elastic deformation, reflects the properties of materials (Hu et al. 2005; Kazemi et al. 2005). The deformation of the material during bending is also an indicator of the mechanical properties of the material.

At present, the mechanical properties of bamboo-wood composite laminates are mainly obtained by measuring the samples in a destructive manner, which has caused certain resource waste (Ashaari et al. 2016; Chung and Wang 2019; Wei et al. 2019). In this paper, the relationship between the properties of component materials and the macromechanical properties of composites is established based on the theory of material mechanics, and the macroscopic mechanical properties were obtained. Xue and Hu (2012) calculated the elastic modulus of laminated veneer lumber using a mix of composite material mechanics, and the results were close to the measured values. Wei et al. (2019) proposed a theoretical model to derive the modulus of elasticity for laminated veneer lumber based on the laminated plate theory, and the validity of the model was proved by experiments.

Numerical simulation has been used to study composite materials by finite element method, which include the bending resistance of oriented particle board reinforced with bamboo and the behavior of oriented strand board beams (Bai et al. 1999; Zhu et al. 2005). Classical theory can theoretically predict the stiffness and strength of LVL and plywood, and the first-order shear deformation theory is used to calculate the deflection of the plate twist specimen, especially for thick, orthotropic laminated composites and sandwich plates (Perry 1948; Wei et al. 2019; Guillén-Rujano et al. 2017).

In this paper, based on an understanding the mechanical properties of component materials, the elastic modulus and deformation of bamboo-wood composite laminates were analyzed using the formulas derived from mechanical theory and numerical simulation by finite element analysis. The results were compared with those by experiments to obtain the relation between the assembly mode of component materials and the properties of composite materials. The schematic of experiments is shown in Fig. 1. This approach helps to reduce traditional trial efforts with theoretical analysis and numerical simulation in the trial production stage of actual production, saving considerable manpower and material resources.

\section{EXPERIMENTAL}

\section{Theoretical Model}

A laminated board, which is a symmetric orthogonal laminated board in a structure, is mainly affected by transverse loads perpendicular to the direction of the board surface. Due to the small Poisson factor, the Poisson effect can be ignored when studying the mechanical model. A section of the laminated beam is intercepted along a specific main direction defined for this research. Therefore, it is assumed that the axis is consistent with the neutral plane of the beam shown in Fig. 2. 


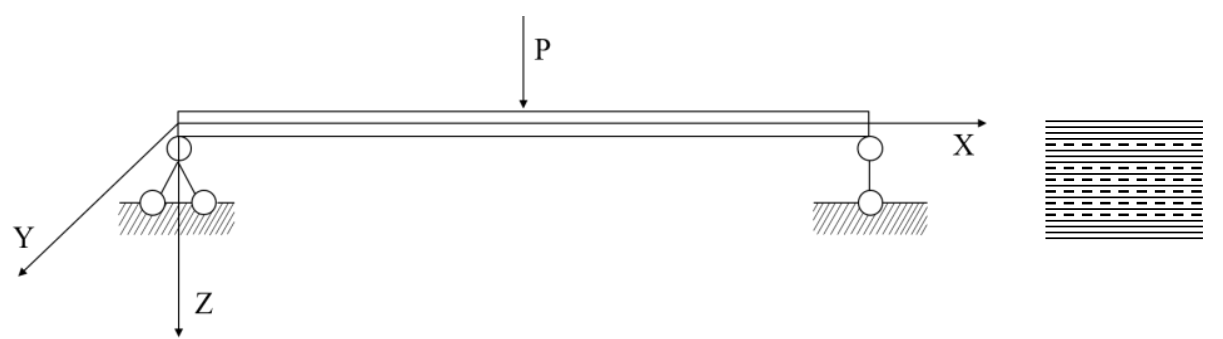

Fig. 2. Schematic diagram of laminated beam (-- bamboo curtain, __ wood veneer)

\section{Classical Theory of Layers and Plates}

(1) Straight line method assumption: The midplane normal direction is still normal to the midplane after deformation, and the thickness remains unchanged; that is, the effect of the transverse shear deformation and the effect of transverse normal stress $\varepsilon_{\mathrm{z}}$ are ignored. The cross-section of the beam is the cross-section perpendicular to the axis of the beam before deformation. After deformation, it is not only perpendicular to the axis, but is also a flat section.

(2) The stress component of the vertical neutral plane in the beam is far less than the in-plane stress value, excluding the effect of $\sigma_{\mathrm{z}}$.

(3) Small deformation hypothesis.

The bending stiffness $D_{\mathrm{i}}$ of the laminated plate with n layers along the two principal axes can be expressed as follows,

$$
D_{\mathrm{i}}=\frac{1}{3} \sum_{K=1}^{\mathrm{n}} E_{\mathrm{i}}^{(\mathrm{k})}\left(z_{\mathrm{k}}^{3}-z_{\mathrm{k}-1}^{3}\right) \quad(\mathrm{i}=\mathrm{x}, \mathrm{y})
$$

where $E_{\mathrm{i}}{ }^{(\mathrm{k})}$ is the bending elastic modulus of the material of the k-th layer of the material in the i-th principal direction of the plate (MPa). $z_{\mathrm{k}}$ and $z_{\mathrm{k}-1}$ are the height coordinates of the upper and lower surfaces of the k-th layer of the material $(\mathrm{mm})$.

According to the equivalent beam theory, the elastic modulus $E_{\mathrm{i}}$ of the laminated plate with $\mathrm{n}$ layers along the two principal axes can be expressed as follows,

$$
E_{\mathrm{i}}=\frac{1}{3 \mathrm{I}} \sum_{\mathrm{K}=1}^{\mathrm{n}} \mathrm{b} E_{\mathrm{i}}^{(\mathrm{k})}\left(z_{\mathrm{k}}^{3}-z_{\mathrm{k}-1}^{3}\right) \quad(\mathrm{i}=\mathrm{x}, \mathrm{y})
$$

where $\mathrm{I}$ is the moment of inertia of the cross-section axis of the laminated beam $\left(\mathrm{mm}^{4}\right)$, and $b$ is the width of the laminated beam $(\mathrm{mm})$.

At this point, the mid-span deflection of the laminated beam is calculated as,

$$
\omega=\frac{P L^{3}}{48 \sum_{\mathrm{k}=1}^{\mathrm{n}} E_{\mathrm{i}}^{(\mathrm{k})} I_{\mathrm{k}}}
$$

where $P$ is the load applied to the laminated beam $(\mathrm{N}), L$ is the length of the laminated beam $(\mathrm{mm}), E_{\mathrm{i}}^{(\mathrm{k})}$ is the same as in Eq. 1 , and $I_{\mathrm{k}}$ is the moment of inertia of the cross-section axis of the k-th layer of the material.

\section{First-order Shear Deformation Theory}

Although the results of the classical theory (CS) are simple to derive and easy to analyze, classical theory does not consider the effect of the transverse shear effect, which will introduce significant error for short beams and a large shear effect. For bamboo-wood composite laminated beams, the material itself has strong anisotropy and a low interlaminar shear modulus. The influence of transverse shear on the bending deformation cannot be ignored. Here, the first-order shear deformation theory (FSDT) may be suitable. 
The first-order shear deformation theory adopts the plane assumption, abandoning the assumption of the straight-line method, namely that the cross-section is still perpendicular to the axis after deformation comparing with the classical theory. According to the first-order shear deformation theory, after the cross-section of a beam is deformed, in addition to the angle change caused by the bending deformation, there is also a part of the angle change caused by the influence of the transverse shear force to reflect the average value and influence of shear deformation of cross section. However, this assumption does not conform to the actual situation. If the plane hypothesis is satisfied, the shear strain should be the same in the thickness direction; then, the generalized Hooke's law and the transverse shear modulus are finite values, and the transverse shear stress is also uniformly distributed along the thickness direction. This does not satisfy the boundary condition when the upper and lower surfaces of the beam are free from shear stress. To compensate for this contradiction, the method of modifying the shear stiffness is generally adopted; that is, the modified shear stiffness $K$ is introduced, which is different for different comparison criteria. In this paper, the shear correction coefficient $K^{2}=5 / 6$ calculated by Pietraszkiewicz et al. (Pietraszkiewicz 1979; Badur 1984; Chróścielewski et al. 2010). For a single layer board, $K^{2}=5 / 6$.

In addition, the elastic modulus $E_{\mathrm{i}}$ of the n-layer laminate along the two principal axes can be derived, which can be expressed as follows,

$$
E_{\mathrm{i}}=\frac{b K L^{2}\left[\sum_{\mathrm{k}=1}^{\mathrm{n}} E_{\mathrm{i}}^{(\mathrm{k})}\left(z_{\mathrm{k}}^{3}-z_{\mathrm{k}-1}^{3}\right)\right]\left(\sum_{\mathrm{k}=1}^{\mathrm{n}} G^{(\mathrm{k})} A^{(\mathrm{k})}\right)}{3 \mathrm{I}\left\{4 \sum_{\mathrm{k}=1}^{\mathrm{n}} b E_{\mathrm{i}}^{(\mathrm{k})}\left(z_{\mathrm{k}}^{3}-z_{\mathrm{k}-1}^{3}\right)+L^{2} K \sum_{\mathrm{k}=1}^{\mathrm{n}} G^{(\mathrm{k})} A^{(\mathrm{k})}\right\}}
$$

where $K$ is the modified shear stiffness coefficient, $G^{(\mathrm{k})}$ is the shear elastic modulus of the $\mathrm{k}$-th layer of the plate $(\mathrm{MPa}), A^{(\mathrm{k})}$ is the cross-sectional area of the k-th layer of the plate $\left(\mathrm{mm}^{2}\right)$, and $E_{\mathrm{i}}^{(\mathrm{k})}, z_{\mathrm{k}}$, and $z_{\mathrm{k}-1}$ are the same as in Eq. 1 , and $b$ and $I$ are the same as in Eq. 2, and $L$ is the same as in Eq. 3. follows,

At this point, the mid-span deflection of the laminated beam is calculated as

$$
\omega=\frac{P L^{3}}{48 \sum_{\mathrm{k}=1}^{\mathrm{n}} E_{\mathrm{i}}^{(\mathrm{k})} \mathrm{I}_{\mathrm{k}}}+\frac{P L}{4 \mathrm{~K} \sum_{\mathrm{k}=1}^{\mathrm{n}} G^{(\mathrm{k})} A^{(\mathrm{k})}}
$$

where $P, L$, and $I_{\mathrm{k}}$ are the same as in Eq. $3, E_{\mathrm{i}}^{(\mathrm{k})}$ is the same as in Eq. 1 , and $G^{(\mathrm{k})}$ and $A^{(\mathrm{k})}$ are the same as in Eq. 4.

\section{Finite Element Method Analysis}

The finite element method (FEM) is a computational approach used in approximating complex real-world engineering problems within certain boundary conditions (Muhammad et al. 2020). The basic idea of it is to discretize the object into a finite number of unit combinations that are connected to each other in a certain way to simulate or approximate the original object. Thus, it simplifies a continuous infinite degree of freedom problem. But it entails dividing the structure into tiny components referred to as elements for static and dynamic analysis under various design constraints (Muhammad and Shanono 2019).

In this study, the SHELL99 element, which is based on the general-purpose finite element analysis software ANSYS, was employed to consider the influence of each layer anisotropy of the laminated beam and the transverse shear effect. Meanwhile, the SHELL99 element is a representative plate and shell element and is a commonly used four- 
node element, where each node has six degrees of freedom, namely, translational degrees of freedom in the $\mathrm{X}, \mathrm{Y}$, and $\mathrm{Z}$ directions and rotational degrees of freedom around the $\mathrm{X}$, $\mathrm{Y}$, and $\mathrm{Z}$ axes. It can be used for layered shell structures. Therefore, this paper constructs a laminated beam model by inputting the physical properties of each layer of the material. When the mechanical properties of bamboo-wood composite laminated plates are tested, the material undergoes elastic deformation. ANSYS software is used to simulate the stress process of elastic deformation. Then, Eq. 6 can be used to calculate the elastic modulus under this method; the largest deformation in the deformation graph of the ANSYS output result is the deflection under the load.

\section{Component Materials and the Assembly Patterns}

The bamboo-wood composite laminated beam shown in Fig. 2 was taken as the analysis object. The direction along the grain of the first layer veneer is considered as the direction of the length of the laminated beam (X direction), as the $\mathrm{Y}$ direction of the horizontal stripes on the board surface and as the $\mathrm{Z}$ direction perpendicular to the board surface (thickness direction). The bamboo-wood composite laminates were assembled based on patterns as shown in Table 1. Before assembling, adhesive was applied to the bamboo curtain and wood veneer, and then the assembling patterns were processed by cold pressing and hot pressing to prepare bamboo-wood composite laminates.

Table 1. Assemble Patterns

\begin{tabular}{|c|c|c|c|}
\hline Layer & Material & Direction & Thickness (mm) \\
\hline 1 & Poplar Veneer & Longitudinal & 1.0 \\
\hline 2 & Eucalyptus Veneer & Transverse & 1.7 \\
\hline 3 & Eucalyptus Veneer & Longitudinal & 1.7 \\
\hline 4 & Eucalyptus Veneer & Longitudinal & 1.7 \\
\hline 5 & Bamboo curtain & Longitudinal & 2.2 \\
\hline 6 & Eucalyptus Veneer & Transverse & 1.7 \\
\hline 7 & Bamboo curtain & Longitudinal & 2.2 \\
\hline 8 & Eucalyptus Veneer & Longitudinal & 2.2 \\
\hline 9 & Bamboo curtain & Longitudinal & 2.2 \\
\hline 10 & Eucalyptus Veneer & Longitudinal & 2.2 \\
\hline 11 & Bamboo curtain & Longitudinal & 2.2 \\
\hline 12 & Eucalyptus Veneer & Longitudinal & 2.2 \\
\hline 13 & Bamboo curtain & Longitudinal & 2.2 \\
\hline 14 & Eucalyptus Veneer & Longitudinal & 2.2 \\
\hline 15 & Eucalyptus Veneer & Transverse & 1.7 \\
\hline 16 & Eucalyptus Veneer & Longitudinal & 1.7 \\
\hline 17 & Bamboo curtain & Longitudinal & 2.2 \\
\hline 18 & Eucalyptus Veneer & Longitudinal & 1.7 \\
\hline 19 & Eucalyptus Veneer & Transverse & 1.7 \\
\hline 20 & Eucalyptus Veneer & Longitudinal & 1.7 \\
\hline 21 & Weedtree Veneer & Longitudinal & 0.6 \\
\hline
\end{tabular}


The mechanical properties of the raw materials (veneer and bamboo curtain) are shown in Table 2 (Cheng 1980; Bai et al. 1999; Li 2006).

Table 2. Properties of the Component Materials

\begin{tabular}{|c|c|c|c|c|}
\hline $\begin{array}{c}\text { Component } \\
\text { Material }\end{array}$ & $\begin{array}{c}\text { Longitudinal Elastic } \\
\text { Modulus (MPa) }\end{array}$ & $\begin{array}{c}\text { Transverse Elastic } \\
\text { Modulus (MPa) }\end{array}$ & $\begin{array}{c}\text { Shear Modulus } \\
(\mathrm{MPa})\end{array}$ & $\begin{array}{c}\text { Poisson's } \\
\text { Ratio }\end{array}$ \\
\hline Poplar Veneer & 7724.5 & 461.7 & 384 & 0.282 \\
\hline Bamboo Curtain & 10641 & 490 & 275 & 0.31 \\
\hline Eucalyptus Veneer & 18900 & 945 & 500 & 0.3 \\
\hline Weedtree Veneer & 20000 & 1000 & 550 & 0.3 \\
\hline Adhesive Layer & 6900 & 6900 & 2650 & 0.3 \\
\hline
\end{tabular}

\section{Bending Test of the Bamboo-Wood Composite laminates}

According to GB/T 17657-2013, the mechanical properties of specimens are tested by the three-point bending method. The thickness of the test piece is fixed, so the span is changed to carry out the test with different span-to-height ratio. The test is divided into three groups, each with six test pieces $(650 \mathrm{~mm} \times 650 \mathrm{~mm})$. During the testing, the loading speed is set to $10 \mathrm{~mm} / \mathrm{min}$, and elastic modulus was calculated with the following formula,

$$
E=\frac{l^{3}}{4 \times b \times t^{3}} \times \frac{\Delta F}{\Delta a}
$$

where $E$ is the elastic modulus of the specimen (MPa), $l$ is the distance between the two supports, $b$ is the width of the specimen $(\mathrm{mm}), t$ is the thickness of the specimen $(\mathrm{mm}), \Delta F$ is the increase of load on the straight line segment of the load-deflection curve $(\mathrm{N})$, and $\Delta a$ is the increment of deformation corresponding to $\Delta F(\mathrm{~mm})$.

\section{Performance Criteria}

Absolute percentage error (APE) was used to evaluate the performance of the three methods in this paper. The equations of these performance criteria are given below,

$$
\mathrm{APE}=\frac{\left|m-m_{d}\right|}{m} \times 100 \%
$$

where $m$ is the measured values, $m_{d}$ is the theoretical values.

\section{RESULTS AND DISCUSSION}

\section{Mechanical Properties without the Adhesive Layer}

Elastic modulus

The elastic modulus $E$ of the laminated beam was calculated according to Eqs. 2, 4 , and 6. The effect of span-to-height ratio of bamboo-wood composite laminates on the elastic modulus was considered. The results are shown in Table 3 ( $x$ and $y$ represent the longitudinal and transverse directions, respectively). The absolute percentage error between predicted and measured elastic modulus is calculated according to Eq. 7. The results are shown in Fig. 3. 
Table 3. Predicted and Measured Modulus of Elasticity

\begin{tabular}{|c|c|c|c|c|c|c|c|c|}
\hline $\mathrm{L} / \mathrm{H}$ & $\begin{array}{c}\mathrm{CS} \\
E_{1 x} / \mathrm{MPa}\end{array}$ & $\begin{array}{c}\mathrm{CS} \\
E_{1 y} / \mathrm{MPa}\end{array}$ & $\begin{array}{c}\mathrm{FSDT} \\
E_{2 x} / \mathrm{MPa}\end{array}$ & $\begin{array}{c}\mathrm{FSDT} \\
E_{2 y} / \mathrm{MPa}\end{array}$ & $\begin{array}{c}\mathrm{FEM} \\
E_{3 x} / \mathrm{MPa}\end{array}$ & $\begin{array}{c}\mathrm{FEM} \\
E_{3 y} / \mathrm{MPa}\end{array}$ & $\begin{array}{c}\text { Meas- } \\
\text { ured } \\
E_{x} / \mathrm{MPa}\end{array}$ & $\begin{array}{c}\text { Measured } \\
E_{y} / \mathrm{MPa}\end{array}$ \\
\hline 10 & 11818.63 & 5576.98 & 9041.18 & 4870.88 & 11368.41 & 5289.32 & 10060 & 3932 \\
\hline 15 & 11818.63 & 5576.98 & 10398.84 & 5239.41 & 11590.43 & 5453.56 & 11090 & 4420 \\
\hline 20 & 11818.63 & 5576.98 & 10975.70 & 5381.93 & 11657.98 & 5509.03 & 11624 & 4703 \\
\hline
\end{tabular}

As shown in Table 3, the longitudinal elastic modulus of the bamboo-wood composite laminates was much greater than the transverse elastic modulus. The elastic modulus predicted by classical theory is not influenced by the span-to-height ratio. The true elastic modulus of the material will not change, but as the span-to-height ratio increases, the elastic modulus predicted by the first-order shear theory and finite element method is increased, and approaches the value predicted by the classical theory. It also can be found that the increment of the elastic modulus decreased with the increase of span-toheight ratio. This shows that the effect of shear decreased with the increase of the span-toheight ratio. Under the same span-to-height ratio, the elastic modulus determined by the first-order shear deformation theory was less than that by the finite element method. In the calculation process, the farther away from the neutral axis, the greater the contribution of veneer or bamboo curtain (the direction must be the same as the laminate direction) to the elastic modulus. This result is similar to the experimental results obtained by Chen et al. (2016). The bamboo curtains are discontinuous. If the bamboo curtains are placed continuously, it will cause larger defects in the composite material. Therefore, the bamboo curtains were not put together. Rather, they were separated with wood veneers, which is also one of the reasons for the assembly patterns used in this article.

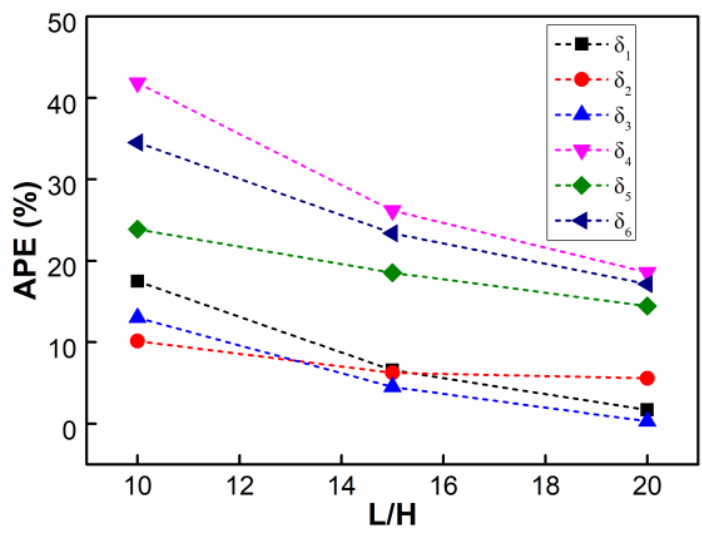

Fig. 3. The absolute percentage error between predicted and measured elastic modulus

As shown in Fig. 3, the $\delta_{1}, \delta_{2}$, and $\delta_{3}$ represent the absolute percentage error between the longitudinal elastic modulus predicted by classical theory, first-order shear deformation theory and finite element method, and the measured longitudinal elastic modulus respectively. The $\delta_{4}, \delta_{5}$, and $\delta_{6}$ represent the absolute percentage error between the transverse elastic modulus predicted by classical theory, first-order shear deformation theory and finite element method, and the measured longitudinal elastic modulus 
respectively. As shown in Fig. 3, the absolute percentage error decreases as the increase of the span-to-height ratio. The absolute percentage error in the longitudinal direction is smaller than those in the transverse direction. This is mainly due to the fact that the shear modulus of component materials has far less influence on the longitudinal elastic modulus of composite materials than its influence on the transverse elastic modulus of composite materials.

\section{Mid-span deflection}

The mid-span deflection $\omega$ of the laminated beam was calculated according to Eqs. 3, 5, and the ANSYS output result. The effect of span-to-height ratio of bamboo-wood composite laminates on the mid-span deflection was considered. The results are shown in Table 4. The absolute percentage error between predicted and measured mid-span deflection is calculated according to Eq. 7. The results are shown in Fig. 4.

Table 4. Predicted and Measured Mid-span Deflection

\begin{tabular}{|c|c|c|c|c|}
\hline $\mathrm{L} / \mathrm{H}$ & $\begin{array}{c}\mathrm{CS} \\
\omega_{1} / \mathrm{mm}\end{array}$ & $\begin{array}{c}\text { FSDT } \\
\omega_{2} / \mathrm{mm}\end{array}$ & $\begin{array}{c}\text { FEM } \\
\omega_{3} / \mathrm{mm}\end{array}$ & $\begin{array}{c}\text { Measured } \\
\omega / \mathrm{mm}\end{array}$ \\
\hline 10 & 1.756 & 2.295 & 1.825 & 2.47 \\
\hline 15 & 5.925 & 6.735 & 6.042 & 8.68 \\
\hline 20 & 14.046 & 15.124 & 14.239 & 22.00 \\
\hline
\end{tabular}

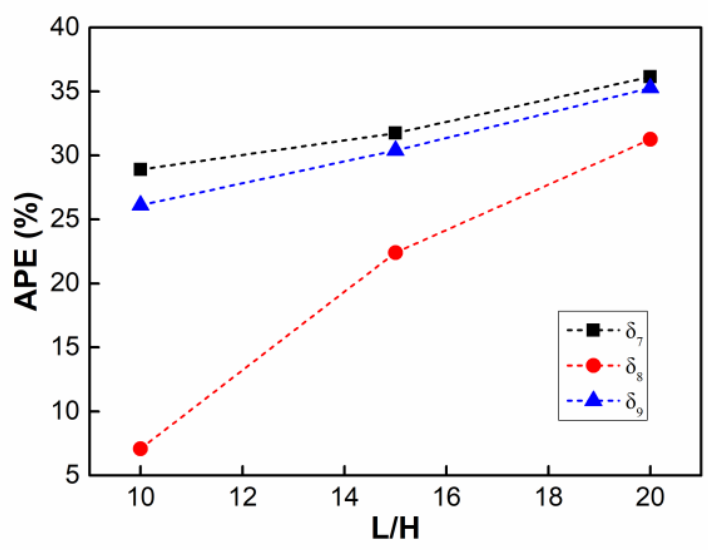

Fig. 4. The absolute percentage error between predicted and measured mid-span deflection

Table 4 shows that as the span-to-height ratio increased, the deflections calculated by the three methods increased geometrically. The mid-span deflection predicted by the three methods are relatively close. As shown in Fig. 4, the $\delta_{7}, \delta 8$, and $\delta 9$ represent the absolute percentage error between the mid-span deflection predicted by classical theory, first-order shear deformation theory and finite element method, and the measured mid-span deflection respectively. As shown in Fig. 4, the absolute percentage error increases as the increase of the span-to-height ratio. Regardless of the span-to-height ratio, $\delta_{8}<\delta_{9}<\delta_{7}$, which shows that the finite element method was superior to first-order shear theory and classical theory in predicting mid-span deflection. The first-order shear theory was better than the classical theory because the first-order shear theory considers the influence of shear strain on bending. 


\section{Mechanical Properties with the Adhesive Layer}

Adhesive layer influence

Many long slits are formed along the fiber direction in the process of weaving bamboo curtains and these are inevitable. The adhesive infiltrates the bamboo and forms three parts in the process of bamboo curtain dipping, drying, cold pressing, and hot pressing. The first part forms an adhesive layer with a certain strength and rigidity on the upper and lower surface of the bamboo by curing, which connects the adjacent bamboo curtains (boards) into a whole. The second part penetrated the bamboo fiber. In the third part, the liquid glue was filled into the slit of the bamboo curtain. This part of the liquid glue solidified into a crisp solidified body almost without pressure and hardly affects the performance of the plywood (Sun 2001).

The adhesive penetrates the veneer, enters the cell cavity, and may even enter the cell wall in the process of veneer coating, assembling, and hot pressing (Furuno et al. 2004; Konnerth et al. 2008; Huang et al. 2012). The portion of the veneer where glue penetrates was considered the glue line, and the results showed that the glue line's influence on the properties of the material can be neglected (Okuma 1976; Wei et al. 2015). The glue that has not penetrated the veneer is cured on the veneer's surface to form an adhesive layer.

The glue line's influence was ignored, and only the influence of adhesive layer on the properties of the composite was considered. The adhesive layer is assumed to be an isotropic wood veneer and with a thickness of $0.0025 \mathrm{~mm}$ (Bai et al. 1999).

\section{Elastic modulus}

The elastic modulus $E$ of the laminated beam was calculated according to Eqs. 2, 4 , and 6. The effect of span-to-height ratio of wood-bamboo composites on the elastic modulus was considered. The results are shown in Table 5. The absolute percentage error between predicted and measured mid-span deflection was calculated according to Eq. 7. The results are shown in Fig. 5.

Table 5. Predicted and Measured Modulus of Elasticity

\begin{tabular}{|c|c|c|c|c|c|c|c|c|}
\hline $\mathrm{L} / \mathrm{H}$ & $\begin{array}{c}\mathrm{CS} \\
E_{4 x} / \mathrm{MPa}\end{array}$ & $\begin{array}{c}\mathrm{CS} \\
E_{4 y} / \mathrm{MPa}\end{array}$ & $\begin{array}{c}\mathrm{FSDT} \\
E_{5 x} / \mathrm{MPa}\end{array}$ & $\begin{array}{c}\mathrm{FSDT} \\
E_{5 y} / \mathrm{MPa}\end{array}$ & $\begin{array}{c}\mathrm{FEM} \\
E_{6 x} / \mathrm{MPa}\end{array}$ & $\begin{array}{c}\mathrm{FEM} \\
E_{6 y} / \mathrm{MPa}\end{array}$ & $\begin{array}{c}\text { Measured } \\
E_{x} / \mathrm{MPa}\end{array}$ & $\begin{array}{c}\text { Measured } \\
E_{y} / \mathrm{MPa}\end{array}$ \\
\hline 10 & 11811.67 & 5578.88 & 9051.44 & 4876.50 & 11362.54 & 5271.52 & 10060 & 3932 \\
\hline 15 & 11811.67 & 5578.88 & 10401.87 & 5243.23 & 11584.32 & 5455.97 & 11090 & 4420 \\
\hline 20 & 11811.67 & 5578.88 & 10974.97 & 5384.97 & 11651.28 & 5511.01 & 11624 & 4703 \\
\hline
\end{tabular}




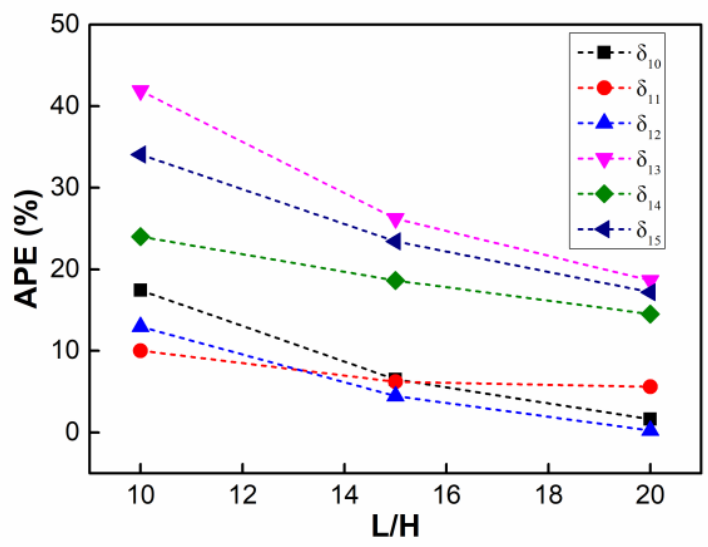

Fig. 5. The absolute percentage error between predicted and measured elastic modulus

As shown in Table 3 and 5, the adhesive layer does not affect the relationship between the elastic modulus and the span-to-height ratio. That is, the elastic modulus predicted by classical theory has nothing to do with the span-to-height ratio, and the elastic modulus predicted by the first-order shear theory and finite element method are increased with the increase in the span-to-height ratio. Compared with the elastic modulus without the adhesive layer, under the classical theory and first-order deformation theory, the transverse elastic modulus with the adhesive layer is greater than that without the adhesive layer, and others are uncertain. Under the classical theory, the longitudinal elastic modulus with the adhesive layer is smaller than that without the adhesive layer. This is inconsistent with our previous theoretical analysis. In the theoretical analysis, it was thought that the elastic modulus with the adhesive layer should be larger than that without the adhesive layer. Combining the formulas of Eqs. 2 and 4, and their derivation process, this is mainly due to the adhesive layer's influence on the stiffness of the laminated board being less than that on the moment of inertia of the section when the elastic modulus of the laminated board reaches a certain level. It is also possible that the elastic modulus of adhesive layer is lower than the longitudinal elastic modulus of wood veneer and higher than the transverse elastic modulus of wood veneer.

It can be concluded from Figs. 5 and 3 that the difference between $\delta_{10}$ and $\delta_{1}, \delta_{11}$ and $\delta_{2}, \delta_{12}$ and $\delta_{3}, \delta_{13}$ and $\delta_{4}, \delta_{14}$ and $\delta_{5}$, and $\delta_{15}$ and $\delta_{6}$ were within $\pm 0.5 \%$, which shows that the adhesive layer had little influence on the elastic modulus. Therefore, the adhesive layer can be ignored when predicting the elastic modulus. When $L / H=20$, the prediction error of longitudinal elastic modulus is less than $6 \%$, and the prediction error of transverse elastic modulus is less than $19 \%$, which shows that these three methods can be used to predict the elastic modulus of composites, and it is more suitable for predicting the longitudinal elastic modulus.

\section{Mid-span deflection}

The mid-span deflection $\omega$ of the laminated beam is calculated according to Eqs. 3, 5, and the ANSYS output result. The results are shown in Table 6. The absolute percentage error between predicted and measured mid-span deflection is calculated according to Eq. 7. The results are shown in Fig. 6. 


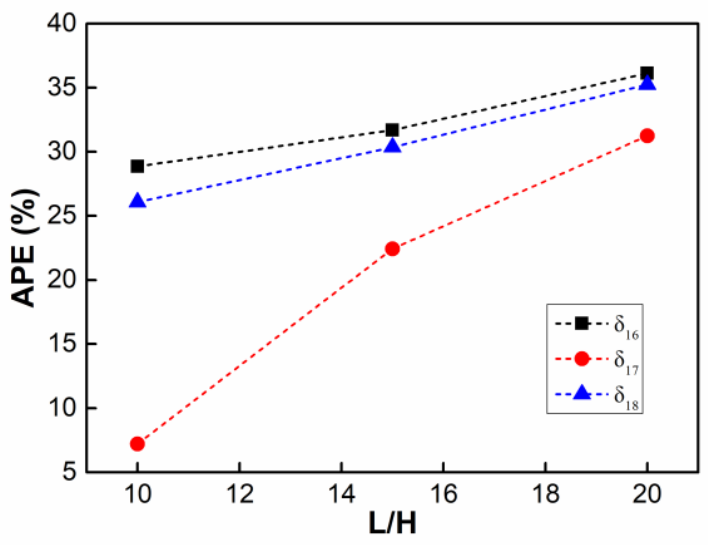

Fig. 6. The absolute percentage error between predicted and measured mid-span deflection

Table 6 shows that as the span-to-height ratio increased, the deflections calculated by the three methods increased geometrically. The mid-span deflection predicted by the three methods were relatively close. As shown in Fig. 6 , the $\delta_{16}, \delta_{17}$ and $\delta_{18}$ represent the absolute percentage error between the mid-span deflection predicted by classical theory, first-order shear deformation theory and finite element method, and the measured mid-span deflection respectively. As shown in Fig. 6, the absolute percentage error increases as the increase of the span-to-height ratio. As can be seen from Fig. 6 and 4, the differences between $\delta_{16}$ and $\delta_{7}, \delta_{17}$ and $\delta_{8}$, and $\delta_{18}$ and $\delta_{9}$ all ranged from $-0.1 \%$ to $0.3 \%$, which shows that the adhesive layer had little influence on the mid-span deflection.

Table 6. Predicted and Measured Mid-span Deflection

\begin{tabular}{|c|c|c|c|c|}
\hline $\mathrm{L} / \mathrm{H}$ & $\begin{array}{c}\mathrm{CS} \\
\omega_{4} / \mathrm{mm}\end{array}$ & $\begin{array}{c}\text { FSDT } \\
\omega_{5} / \mathrm{mm}\end{array}$ & $\begin{array}{c}\text { FEM } \\
\omega_{6} / \mathrm{mm}\end{array}$ & $\begin{array}{c}\text { Measured } \\
\omega / \mathrm{mm}\end{array}$ \\
\hline 10 & 1.757 & 2.292 & 1.826 & 2.47 \\
\hline 15 & 5.929 & 6.733 & 6.045 & 8.68 \\
\hline 20 & 14.054 & 15.125 & 14.247 & 22.00 \\
\hline
\end{tabular}

\section{CONCLUSIONS}

1. The transverse shear effect affects the mechanical properties of the material. As the span-to-height ratio increases, the transverse shear effect becomes smaller and smaller.

2. The effect of the adhesive layer on the elastic modulus and deflection was $\pm 0.5 \%$ and $-0.1 \%$ to $0.3 \%$, and it was not necessary to consider the adhesive layer when predicting the elastic modulus and deflection. However, the adhesive layer is unavoidable in the process of perfecting the laminate model. In this respect, the adhesive layer is still worthy of continued research.

3. When $L / H=20$, the prediction error of longitudinal elastic modulus is less than $6 \%$, and the prediction error of transverse elastic modulus is less than $19 \%$, which shows that these three methods can be used to predict the elastic modulus of composites, and it is more suitable for predicting the longitudinal elastic modulus.

4. On the basis of knowing the properties of component materials, it is feasible to predict 
the properties of composite materials through theoretical calculations and numerical simulations, which can reduce the traditional trial production work and save a lot of manpower and material resources.

\section{ACKNOWLEDGMENTS}

The authors are grateful for the support of the National Natural Science Foundation of China (31660174), and the Guangxi Innovation-Driven Development Special Fund Project of China (AA17204087-16).

\section{REFERENCES CITED}

Ashaari, Z., Lee, S. H., and Zahali, M. R. (2016). "Performance of compreg laminated bamboo/wood hybrid using phenolic-resin-treated strips as core layer," European Journal of Wood and Wood Products 74(4), 621-624. DOI: 10.1007/s00107-0161027-0

Bai, X. S., Lee, A. W. C., Thompson, L. L., and Rosowsky, D. V. (1999). "Finite element analysis of Moso bamboo-reinforced southern pine OSB composite beams," Wood and Fiber Science 31, 403-415.

Badur, J. (1984). "Non-linear analysis of elastic shells according to second approximation to the strain energy," Institute of Fluid-Flow Machinery PASci, Gdan sk, Poland.

Banik, N. (2018). "An experimental effort on the impact of hot press forming process parameters on tensile, flexural and impact properties of bamboo fiber composites with the help of Taguchi experimental design," Materials Today: Proceedings 5(9), 20210-20216. DOI: 10.1016/j.matpr.2018.06.391

Banik, N. (2020). "Manufacturing of bamboo composite in the industrial aspect," Materials Today: Proceedings 26, 2875-2887. DOI: 10.1016/j.matpr.2020.02.596

Chen, F., Deng, J., Li, X., Wang, G., Smith, L. M., and Shi, S. Q. (2016). "Effect of laminated structure design on the mechanical properties of bamboo-wood hybrid laminated veneer lumber," European Journal of Wood and Wood Products 75(3), 439-448. DOI: 10.1007/s00107-016-1080-8

Cheng, J. Q. (1980). Identification, Wood Properties and Utilization of Tropical and Subtropical Wood in China, China Forestry Press, Beijing, China.

Chróścielewski, J., Pietraszkiewicz, W., and Witkowski, W. (2010). "On shear correction factors in the non-linear theory of elastic shells," International Journal of Solids and Structures 47(25-26), 3537-3545. DOI: 10.1016/j.ijsolstr.2010.09.002

Chung, M. J., and Wang, S. Y. (2019). "Physical and mechanical properties of composites made from bamboo and woody wastes in Taiwan," Journal of Wood Science 65(1). DOI: 10.1186/s10086-019-1833-1

Ettelaei, A., M. Layeghi, H., Hosseinabadi, Z., and Ebrahimi, G. (2019). "Prediction of modulus of elasticity of poplar wood using ultrasonic technique by applying empirical correction factors," Measurement 135, 392-399. DOI: 10.1016/j.measurement.2018.11.076

Furuno, T., Imamura, Y., and Kajita, H. (2004). "The modification of wood by treatment with low molecular weight phenol-formaldehyde resin: A properties enhancement with neutralized phenolic-resin and resin penetration into wood cell walls," Wood 
Science and Technology 37(5), 349-361. DOI: 10.1007/s00226-003-0176-6

Guillén-Rujano, R., Hernández-Pérez, A., and Avilés, F. (2017). "Examination of the plate twist specimen for thick specially orthotropic laminated composites and andwich plates by using first-order shear deformation theory," Journal of Sandwich Structures \& Materials 21(7), 2239-2265. DOI: 10.1177/1099636217748349

Guo, N., Chen, H. H., Zhang, P. Y., and Zuo, H. L. (2016). "The research of parallel to the grain compression performance test of laminated glued bamboo-wood composites," Tehnicki Vjesnik-Technical Gazette 23(1), 129-135. DOI: 10.17559/TV20160108190015

Hu, Y. C., Wang, F. H., Gu, J. Y., Liu, Y. X., and Nakao, T. (2005). "Nondestructive test and prediction of modulus of elasticity of veneer-overlaid particleboard composite," Wood Science and Technology 39(6), 439-447. DOI: 10.1007/s00226-005-0013-1

Huang, Y. H., Fei, B. H., Yu, Y., and Zhao, R. J. (2012). "Effect of modification with phenol formaldehyde resin on the mechanical properties of wood from Chinese fir," BioResources 8(1), 272-282. DOI: 10.15376/biores.8.1.272-282

Kazemi Najafi, S., Bucur, V., and Ebrahimi, G. (2005). "Elastic constants of particleboard with ultrasonic technique," Materials Letters 59(16), 2039-2042. DOI: 10.1016/j.matlet.2005.02.013

Konnerth, J., Harper, D. Lee, S.-H., Rials, T. G., and Gindl, W. (2008). “Adhesive penetration of wood cell walls investigated by scanning thermal microscopy (SThM)," Holzforschung 62(1), 91-98. DOI: 10.1515/HF.2008.014

Lee, C. H., Chung, M. J., Lin, C. H., and Yang, T. H. (2012). "Effects of layered structure on the physical and mechanical properties of laminated moso bamboo (Phyllosachys edulis) flooring," Construction and Building Materials 28(1), 31-35. DOI: 10.1016/j.conbuildmat.2011.08.038

Li, J. (2006). Prediction of Mechanical Properties and Structural Optimization of Bamboo/Wood Composite Laminates, Master's Thesis, Nanjing Forestry University, Nanjing, China.

Liliefna, L. D., Nugroho, N., Karlinasari, L., and Sadiyo, S. (2020). "Development of low-tech laminated bamboo esterilla sheet made of thin-wall bamboo culm," Construction and Building Materials 242, 118181. DOI: 10.1016/j.conbuildmat.2020.118181

Muhammad, A., Ali, M. A. H., and Shanono, I. H. (2020). “ANSYS - A bibliometric study," Materials Today: Proceedings 26, 1005-1009. DOI: 10.1016/j.matpr.2020.01.192

Muhammad, A. and Shanono, I. (2019). "Static analysis and optimization of a connecting rod," International Journal of Engineering \& Technology Sciences 6, 24-40. DOI: 10.15282/ijets.6.1.2019.1003

Okuma, M. (1976). "Plywood properties influenced by the glue line," Wood Science and Technology 10(1), 57-68. DOI: 10.1007/BF00376385

Perry, T. (1948). Modern Plywood, Pitman Publishing Corp, New York.

Pietraszkiewicz, W. (1979). "Consistent second approximation to the elastic strain energy of a shell," Z. Angew. Math. Mech. 59, 206-208.

Rao, J. P., Bao, L. X., Wang, B. W., Fan, M. Z., and Feo, L. (2018). "Plasma surface modification and bonding enhancement for bamboo composites," Composites Part BEngineering 138, 157-167. DOI: 10.1016/j.compositesb.2017.11.025

Sun, F. W. (2001). Mechanical Properties Model Theory and Strength Prediction of Bamboo-wood Composite Container Floor Structure, Ph.D. Dissertation, Nanjing 
Forestry University, Nanjing, China.

Verma, C. S., Sharma, N. K., Chariar, V. M., Maheshwari, S., and Hada, M. K. (2014). "Comparative study of mechanical properties of bamboo laminae and their laminates with woods and wood based composites," Composites Part B-Engineering 60, 523530. DOI: 10.1016/j.compositesb.2013.12.061

Wei, P. X., Rao, X., Wang, B. J., Dai, C. P., Wei, P. X., and Zhou, D. G. (2015). “A modified theory of composite mechanics to predict tensile modulus of resinated wood," Wood Research 60(4), 567-582.

Wei, P. X., Wang, B. J., Wan, X. J., and Chen, X. H. (2019). "Modeling and prediction of modulus of elasticity of laminated veneer lumber based on laminated plate theory," Construction and Building Materials 196, 437-442. DOI: 10.1016/j.conbuildmat.2018.11.137

Wei, P. X., Wang, B. J., Wang, L. B., Wang, Y. Q., Yang, G. R., and Liu, J. H. (2019). "An exploratory study of composite cross-laminated timber (CCLT) made from bamboo and hemlock-fir mix," BioResources 14(1), 2160-2170. DOI: 10.15376/biores.14.1.2160-2170

Xue, B., and Hu, Y. (2012). "Mechanical properties analysis and reliability assessment of laminated veneer lumber (LVL) having different patterns of assembly," BioResources 7(2), 1617-1632. DOI: 10.15376/biores.7.2.1617-1632

Zhu, E. C., Guan, Z. W., Rodd, P. D., and Pope, D. J. (2005). "Finite element modelling of OSB webbed timber I-beams with interactions between openings," Advances in Engineering Software 36(11-12), 797-805. DOI: 10.1016/j.advengsoft.2005.03.027

Article submitted: June 28, 2021; Peer review completed: August 10, 2021; Revised version received and accepted: September 11, 2021; Published: October 4, 2021.

DOI: $10.15376 /$ biores.16.4.7784-7798 